\title{
Urban Secondary Teachers' Value Orientations: Delineating Curricular Goals for Social Responsibility
}

\author{
Catherine D. Ennis \\ University of Maryland
}

\begin{abstract}
This research examined content and task decisions of 11 urban secondary physical educators who placed a high priority on social curriculum goals. Transcript data from a stimulated-recall protocol were analyzed using constant comparison to determine the extent to which content and task decisions represented social justice and reform goals of social reconstruction or of citizenship and positive interaction more consistent with social responsibility. Results suggested that teachers' content decisions were consistent with the goals of cooperation, teamwork, and involvement within the social responsibility value orientation. Task structures for middle school programs involved large group activities, while high school tasks focused on individual activities performed as a member of a small group.
\end{abstract}

Value orientations represent educational values or beliefs influential in curricular decision making. These orientations determine, in part, which content topics will be emphasized during instruction and the extent to which the content will be learned. In urban school districts the decisions are often dominated by efforts to assist students in learning social and cognitive skills that lead to a positive future (Page, 1990). In physical education, the limited time and resources allocated to programs, coupled with increasing class sizes, often force teachers to select curriculum goals they judge most important for their students. Although goals often include skill, sport, and fitness objectives, there is increasing evidence (e.g., Ennis, Ross, \& Chen, 1992) that some physical educators include affective goals such as getting along and respect for others as primary foci of their programs. This seems to be especially true in urban schools where discontent and violence in neighborhoods often spill into classrooms (Cohn, 1992).

Research by Ennis, Ross, and Chen (1992) indicated that some high school physical educators who taught in highly diverse ethnic and socioeconomic urban schools perceived that the major goal of physical education was to socialize students within the rules and norms of the school and gymnasium. Although their inclusion of sport content had not changed over the years, teachers reported that their curriculum focus within sport units had shifted from skill and strategy

Catherine D. Ennis is with the Department of Kinesiology at the University of Maryland, College Park, MD 20742-2611. 
development to an emphasis on social goals such as respect for others and positive group interaction (Ennis, 1992). Ennis, Ross, and Chen reported that in the past social goals had been used as process goals to create an orderly environment necessary when teaching sport; however, with the levels of violence in neighborhoods and schools, teachers now perceived social goals as valued products of the physical education curriculum.

Research by Ennis and her colleagues (Ennis, Chen, \& Ross, 1992; Ennis \& Zhu, 1991) examined five belief systems or value orientations influential in physical educators' curricular decision making. Two orientations, disciplinary mastery and learning process, place the body of knowledge as the central focus of the teaching-learning process, whereas the other three orientations-selfactualization, ecological integration, and social reconstruction-emphasize intrapersonal and interpersonal goals as the primary physical education focus. Schoolbased research suggested that the majority of the orientations accurately reflected teachers' curricular value perspectives. However, research by Ennis, Ross, and Chen (1992) indicated that the social reconstruction focus was problematic. Specifically, the social justice and reform focus of this orientation was not evident in teacher comments. Instead, teachers reported a social focus on teamwork, cooperation, and respect more consistent with the construct of social responsibility (Wentzel, 1991a). Social responsibility is a curricular goal that some educators believe contributes directly to student success through student socialization, personal agency, citizenship, and interactive problem solving. Wentzel (1991b) explained that "character development and social responsibility in general have been stated as explicit objectives for public schools in almost every educational policy statement since 1848 , being promoted with the same frequency as academic skills" (p. 2). Ford, Wentzel, Wood, Stevens, and Siesfeld (1989) reported survey research findings indicating that both "adults and adolescents believe that social responsibility is the most important social goal for young people to have attained by age 18 "' (p. 406).

The purpose of this research was to describe the content and task decisions of urban secondary physical education teachers who placed a high priority on social-curricular goals. Specifically, data were analyzed to determine the extent to which teachers advocated a social reconstruction or responsibility perspective. A stimulated recall protocol was used to assist teachers in discussing their content decisions as they occurred in the classroom and to articulate relationships between content goals and tasks. The significance of this research lies in our ability to conceptualize urban teachers' goals for social curricula through specific content and tasks that they believe are most appropriate for their students. The delineation of interpersonal social goals as explicit curricula, rather than issues of class control or management (e.g., McBride, Boggess, \& Griffey, 1986), can assist supervisors in developing a greater sensitivity to these issues and in addressing them explicitly in curriculum and staff development. This information may also be useful to teacher educators in their efforts to teach preservice teachers to conceptualize and implement affective goals in physical education.

\section{Value Orientations}

Value orientations reflect priorities that teachers place on particular goals and objectives for curriculum decision making. These include both academic 
goals associated with the body of knowledge in the discipline and affective goals related to the learner's needs and interests and the social context. Kliebard (1988) explained that because curriculum reflects the diverse cultures and values in which we live, "one would expect that first one current (or curriculum focus) and then another should assume prominence and that, to some extent, they should all exist side by side"' (p. 30). Goals competing for priority within the teachers' value system have been articulated within the curriculum literature (e.g., Atkins, 1986; Eisner \& Vallance, 1974; McNeil, 1990) as the value orientations of disciplinary mastery, learning process, self-actualization, ecological integration, and social reconstruction.

The value orientations of disciplinary mastery and learning process focus curricular decisions on the body of knowledge within the discipline. The disciplinary mastery orientation places a priority on the mastery of the traditional body of knowledge within each subject area (Bloom, 1981). In physical education, students are expected to demonstrate proficiency on a comprehensive range of objectives within skill, sport, and fitness content (Rink, 1993; Siedentop, 1991). Learning-process advocates use disciplinary knowledge as the foundation for the development of problem-solving and decision-making skills. Students are encouraged to develop the questioning and analytic skills necessary to learn independently (Bruner, 1977). Physical educators frame specific problems to challenge students to learn conceptually and to identify commonalities across movement, sport, and exercise content (Lawson \& Placek, 1981). Although advocates of both orientations value the role of knowledge as the central focus of the educational process, disciplinary mastery teachers place the curricular emphasis on mastery of a comprehensive set of facts, whereas learning-process teachers use knowledge to enhance thinking and problem-solving skills.

The value orientations of self-actualization, ecological integration, social reconstruction, and social responsibility focus on the affective skills necessary for personal and social success. The self-actualization orientation is based on the work of Maslow (1979) and Rogers (1983). In physical education, the curricular focus is placed on the needs and interests of students as perceived by both the student and the teacher. Subject-matter knowledge is viewed as a means to the end of enhancing student success and personal feelings of self-esteem and selfconcept (e.g., Rockett \& Owens, 1977). The ecological integration value orientation was first articulated by Dewey (1916) and has been interpreted by Colwell (1985) and Jewett and Ennis (1990). In physical education, advocates (e.g., Jewett \& Mullan, 1977) balance curricular priorities to place a relatively equal emphasis on the student, the knowledge base, and the social context. Physical educators who advocate this perspective argue that ecological integration is a realistic approach to understanding and functioning within complex educational environments.

Learning goals within the social domain can be articulated as an emphasis on social justice and reform as advocated by social reconstructionists or goals to promote citizenship and respect for others as proposed by social responsibility advocates. Social-reconstruction teachers encourage students to become aware of inequities, develop a commitment to reform, and design strategies for change (Banks, 1991). Social, political, and economic factors are viewed as facilitators or constraints in the change process (Apple, 1982). In physical education, Griffin (1985) identified strategies useful in promoting sex equity. Social responsibility 
advocates focus on curricular goals to enhance students' respect and understanding of others. Students are encouraged to become involved in group activities and to use their unique abilities to further group goals (Wentzel, 1991b). Subjectmatter knowledge provides opportunities for students to interact and to solve group problems. Teachers place the curricular priority on content and tasks that encourage students to develop positive interpersonal skills leading to social competence (Hellison, 1985; Solomon, Watson, Delucchi, Schaps, \& Battistich, 1988).

Value orientations, as presented in the curriculum literature, reflect pure perspectives on curricular decision making. In reality, teachers are influenced by a number of value perspectives that blend to influence their curricular and instructional plans. Although it is relatively easy to identify value orientations in the curriculum literature, it is more challenging to describe the influence of teachers' value perspectives in their daily decision making. Ennis and Hooper (1988) developed the Value Orientation Inventory (VOI) to examine teachers' goals for curricular decision making. The iriventory utilizes a forced-choice format to determine teachers' educational priorities within the disciplinary mastery, learning process, self-actualization, ecological integration, and social reconstruction value orientations. Social responsibility is not included in the VOI. Items are written to reflect potential goals, tasks, and instructional strategies consistent with each orientation. The VOI profile reflects the respondents' score on each of the five orientations relative to the others. Rather than arguing for the dominance of one perspective, it seems more valid to present evidence to support the priority of each orientation within the teacher's educational belief system.

Research to examine teachers' value orientations has described the relative strength of each orientation within the value profile (Ennis, Chen, \& Ross, 1992; Ennis \& Zhu, 1991) and reported detailed descriptions of educational goals and strategies advocated by teachers with a high priority for a particular orientation (Ennis, Ross, \& Chen, 1992). Ennis and Zhu (1991) examined physical educators' educational value orientations in three midwestern school districts. Both the teachers and the students were predominately white and middle class. Results indicated that $97 \%$ of the teachers placed a consistent priority on one or more value orientations. They thought reflectively about curricular and teaching decisions and knew consciously or intuitively how to select items reflecting a consistent value orientation. Teachers in this sample were equally likely to place a high priority on items representing each value orientation.

Ennis, Chen, and Ross (1992) replicated this study with secondary physical education teachers in a large urban school district (enrollment over 115,000) on the East coast. Teachers were predominately white $(80 \%)$, and the majority of their students were black $(86 \%)$. Results indicated that $57 \%$ of teachers placed a high priority on the social reconstruction orientation, and only $7 \%$ placed a high priority on the academic items within the disciplinary mastery orientation. A follow-up study (Ennis, Ross, \& Chen, 1992) compared the goals and expectations of teachers who placed a high priority on the disciplinary mastery and learning process (DM/LP) goals with teachers who valued the ecological integration and social reconstruction (EI/SR) orientations. Results suggested that DM/ LP teachers' goals and beliefs were consistent with those articulated in the literature for cognitively oriented programs. However, the EI/SR teachers' goals appeared to represent a social responsibility rather than a social reconstruction 
orientation. EI/SR teachers reported a strong emphasis on social interaction, cooperation, and enjoyment.

The findings reported in this study represent one part of a study to examine teachers' selections of social goals for physical education. This research examined the content and task decisions of teachers who placed a high priority on the social reconstruction value orientation on the VOI. Content decisions focused on the selection of curricular goals within the physical education program, and tasks represented implementation decisions regarding how the content should be presented to students (e.g., teaching styles, activities). Specifically, responses to stimulated recall protocols were analyzed to determine the extent to which they reflected the social justice and reform goals of the social reconstruction orientation or social responsibility goals similar to those identified by Ennis, Ross, and Chen (1992).

\section{Method}

\section{Subjects}

Subjects were 5 high school and 6 middle school physical education teachers who had placed a high priority on the social reconstruction value orientation on the VOI. Teachers' VOI scores were used to screen and select teachers who placed a high priority on the social reconstruction orientation. Teachers with social reconstruction orientation scores less than 51.25 , the criterion score designating a high priority, were included in the study. Teachers selected for this study had been teaching from 16 to 34 years and averaged 25.6 years of experience. They taught in nine different schools. Nine teachers were white and 2 were African American. Six teachers in the sample were female. The male and female teachers at two schools combined their classes and taught as a team. Enrollments for individual classes ranged from 25 to 45 students, and team-taught classes averaged 85 students. All classes were taught in a gymnasium or athletic field. The majority of students in these classes were African American (86\%) and represented lower and middle socioeconomic families. The school district was one of six encompassing a large metropolitan area. The enrollment of this district was over 115,000. Each teacher was informed of the research purpose and the manner in which data would be used.

\section{Value Orientation Inventory (VOI)}

Value Orientation Inventory scores were used to select teachers for the study. The inventory was developed by Ennis and Hooper (1988) to examine teachers' value orientation profiles. The VOI is a forced-choice instrument consisting of 15 sets of 5 items, with one item in each set representing each value orientation. Teachers rank items to reflect their curricular and instructional priorities. The alpha coefficient for disciplinary mastery is .91 , for learning process .79 , for self-actualization .77, for ecological integration .91 , and for social reconstruction .84. Items are unlabeled and placed randomly in the sets. Scores for each value orientation are divided into high and low priority based on .6 standard deviation. 


\section{Data Collection}

A stimulated recall protocol was used to elicit data regarding teachers' content decisions and rationales for task selection. The investigator videotaped two different classes for each teacher or teaching team. Classes were videotaped at least one month apart and consisted of different content emphases. Teachers wore a wireless microphone to facilitate the recording of instructions and comments on the videotape. The audio portion of the videotape was transcribed and used in the analysis. Teachers met with the researcher to discuss the videotape within 24 hours of each filming. It was usually possible to schedule the meeting during the teacher's planning or lunch period, immediately following the videotaped class. In team teaching situations, both teachers were interviewed together.

The session following the first videotaping began with a brief discussion of school and student characteristics. Teachers also provided demographic information about the length of time they had been teaching and the extent of their other school responsibilities, such as hall, lunch, and bus duty. Teachers were then asked to watch the videotape and were instructed to stop the tape or rewind it to review segments. They explained the purpose of each activity and why they had selected these particular tasks to convey their goals. The researcher asked probing questions to elicit information regarding the teachers' rationale for the content decision and the characteristics of each task that made it a candidate to convey a specific goal or objective. This procedure was followed for both stimulated recall sessions. Each meeting was audiotaped and transcribed for analysis.

\section{Data Analysis}

Transcript data from the videotaped classes and the stimulated recall sessions were analyzed using constant comparison (Glaser \& Strauss, 1967; Goetz \& LeCompte, 1984). Constant comparison is a four-step process consisting of scanning the data for common categories, identifying properties or common themes, positioning the data within common categories, and developing explanatory theory. In this study, teachers commented on student, school, and curriculum activities as they viewed the videotapes, resulting in a wide range of categories. Data from each interview were first scanned to identify categories and subcategories. Critical properties for each category were delineated within the specific teaching context in which it was identified. These two steps were then repeated for the videotape transcriptions. In the third stage the data from the stimulated recall and teachers' class comments from the videotapes were compared by subcategory. In Stage 4 the data were compared with results from other research on teachers' social goals to place the current research within a broad educational and contextappropriate perspective.

\section{Results}

Teachers' content decisions indicated a strong emphasis on interpersonal skills as the focus of the program. They discussed the importance of content associated with cooperation, teamwork, and involvement for students in their classes. Tasks selected to convey these goals were primarily team sport activities at the middle schools and group-oriented learning environments for individual tasks at the high schools. 


\section{Content Decisions}

These teachers had almost complete control over the content decisions in their classrooms. The decisions appeared to be influenced by their perceptions of student needs, especially those associated with the context in which students lived. They reported that their students lacked the interpersonal skills necessary to cooperate with others in their neighborhoods and in the classroom. The following categories represent teacher-defined perspectives on social content. Teachers argued that content associated with cooperation, teamwork, and involvement was instrumental in assisting students to live and perform successfully in school and throughout their lives.

Cooperation. Teachers explained that cooperation was a central goal of their curriculum. They argued that cooperation was a "necessary part of being with other people." Joan, a high school teacher, defined cooperation as "getting along with other students." Other teachers added that "cooperation means that students are working together to accomplish something." Students were expected to cooperate with the teacher as well as with other students in the class. Teachers perceived cooperation to be essential not only for sharing equipment in large classes but also for taking turns, playing by the rules, and facilitating a smooth class. Teachers pointed out that there were particular reasons why these students needed to learn cooperation and why, in some instances, students had difficulty cooperating. Ellen, a middle school teacher, commented:

Most of my students come from low socioeconomic families. They often have to sleep in the same bed with older or younger brothers or sisters. After school and on weekends they must look after younger siblings while trying to play with their own friends. They are never alone.

Teachers reported that the biggest difficulty in teaching students to work cooperatively was in convincing them to make their own needs and interests subservient to the group's needs or goals. A subservient image was a direct contradiction to the independence and autonomy that many students experienced outside of school. They described their students as "not well supervised at home." Students were relatively independent from the time they left school until they returned the next morning. Teachers reported that during this time students, both boys and girls, spent most of their time trying to gain status and position in their neighborhood groups. Although group members would protect each other when threatened from outside, most of their out-of-school time focused on establishing and maintaining their social position within the group. Tom, a high school teacher, explained:

At the beginning of the school year my kids were not interested in working cooperatively with others. They initially perceived this as a show of weakness that diminished their status with their friends. They were used to getting what they wanted by force. . . . That often involves fighting. I almost have to redefine what a group or a team is. When you talk about cooperation, you have to convince them that by helping others to achieve, they are also helping themselves.

Jocelyn described her middle school students as afraid to work closely with others because of a fear of being perceived as weak or "needy." She explained 
that her cooperative content focused on solving problems with other people. Problems might involve the subject matter of games and sports or simple management tasks that are required to prepare the group or team for participation. Her criterion for a "good" social task or problem is that the task requires every member of the group to contribute. She reported that group problem-solving strategies were effective in enhancing social interaction. However, problem solving often led to social conflicts that, in turn, had to be handled positively:

If you don't have a decent cooperation level between you and the students and among the students themselves, you are going to have fighting all the time. Last week I assigned the seventh-grade team captains the simple task of assigning each person on their team to a specific batting order for our softball game. . . At least with other classes it had been simple. But with this group, all the boys on one team wanted to bat first, and the girls didn't want to bat at all. I spent 15 minutes talking about cooperation . . . that everybody had to work together to be successful. They finally agreed on an order where boys and girls alternated. Several of the boys really didn't like it, but at least they agreed to do it.

Cooperation was one of the most salient goals reported by these teachers. Videotape transcripts indicated that the teachers spoke to students frequently about the importance of cooperation for success in school and in life. Teachers stopped the class at regular intervals to reinforce and reaffirm these goals. Learning to cooperate appeared to be of greater importance to teachers than academic goals. Bill, a high school teacher, said, "Your subject matter is secondary. The skill they can learn anywhere. The group interaction is what I teach. If I don't teach it, where else will they learn it?" Teachers appeared to place a greater verbal emphasis on cooperation than on teaching content associated with skills and fitness. Their comments about cooperation usually involved a specific concrete goal to be accomplished with a minimum of disagreement. It involved majority rule with an emphasis on the subservience of individual preferences to a general set of group goals.

Teamwork. Content focusing on teamwork emphasized concrete strategies to accomplish team goals. Although cooperation was group oriented, the goals were nebulous and frequently related to students managing themselves. When content focused on teamwork, the team was charged with a specific objective usually requiring athletic ability, concentration, and helping others. Teachers specifically commented about students helping each other to score or win in team play. As they viewed the videotapes, the teachers seemed especially pleased when helping behaviors between teammates occurred spontaneously and without their assistance. Betty, a high school teacher, stopped the tape after a successful flag football play and exclaimed:

Yes! There ... right there ... did you see that? Sean threw a good pass to Tamika. It was a good pass because it was one she could catch . . . not too hard. He just lobbed it over the defender's head . . . right into her arms. And she caught it! Sean was as excited as Tamika. Now that was an example of good teamwork . . . being sensitive to the needs of people on your team and placing them in a situation to be successful. 
Sue and Bob, middle school team teachers, reported that they emphasized teamwork activities in stressful game situations:

Sue: We have been working with our students all year on teamwork, and they do a pretty good job with it in day-to-day situations. But it's when the pressure is on in our team-competition days that we see how well they are doing.

Bob: Last week we finished our volleyball unit with an eight-team tournament. Each of the teams was evenly matched and the scores were pretty close. Students started criticizing teammates for mistakes, arguing, and complaining about the rules. We even had two fights break out. . . . We finally stopped the tournament and sat everyone down to talk about the importance of teamwork under pressure. It doesn't matter how skilled you are or how much you know. If you can't work together as a team, you are not going to be successful.

Teamwork represented a principal content goal for these teachers. They reported that many of the interpersonal skills, such as helping others, and developing respect and understanding for others were best taught with a focus on teamwork. Four teachers emphasized that although difficult team members initially caused problems, it was important for the group to continue to work with that person and to bring him or her into the group. Jocelyn said, "Even though the team suffers because of one person, in the long run you are going to gain a lot because that person is going to turn around for you.",

Group affiliation was identified as a critical component for successful teamwork. Teachers reported that they planned activities to help students "feel as one as a class." Videotape transcripts indicated they took time to encourage students to communicate with each other and to place the group's needs above their own preferences. Sally and Ron, middle school team teachers, reported they emphasized the role of communication when encouraging students to affiliate with their group or team:

Ron: We know when teams are not getting along. Seventh and eighth graders are quick to complain about other group members. We talk individually to the person supposedly causing the problems, and then we go back to the group members to assist them to work through the problem.

Sally: Most of the time it is poor communication. Someone gets angry because he or she doesn't think the team is including them. They want to be part of the team, but they simply don't know how to approach the group. We talk to everyone together and explain that if a student is not playing the way you want, it is probably because the group is not treating them the way they want to be treated.

Teachers reported that they used incentives to encourage students to affiliate with the team. Teams were assigned both positive and negative bonus points based on their behavior and ability. The team was awarded points based on the ability of team members to answer questions about the sport rules or strategies. They were given additional points for performing a skill correctly regardless of whether the skill led to scoring points within the rule structure of the game. However, students who were not prepared for class not only lost points from 
their own grade but the team was also penalized through a loss of team points. Failure to sit quietly or work together as a team resulted in a similar loss of points.

Content decisions regarding teamwork were primarily sport related and depended on the development of a sense of group affiliation. Students were placed in stressful situations and encouraged to help others. Affiliation with the group took precedent over personal goals. Teachers reiterated that learning to interact socially was of critical importance to school success for these students: "They can learn to play the sport anywhere, it is our job to teach them to work together as a team."

Involvement. The content decisions to encourage students to become involved in class stemmed from the fact that many students in these programs did not want to participate in class activities. Teachers believed this was due to a lack of motivation, fear of failure, and a perception that peers did not value the activity. In sport-based programs this often resulted from a dislike for a particular sport, displeasure with particular team members assigned to one's team, or the physical demands of participation, such as the fear of breaking designer-painted fingernails. Several middle school teachers reported their curriculum included different activities in an effort to maintain student interest. Ellen pointed out, "The theme is variety, variety to capture interest, variety to motivate." Sport units changed every 2 weeks so that students who were displeased with the unit would not have to endure it for too long. Bill explained:

Most of the content consists of sports we know they enjoy, although there are some cultural differences. We give them choices about the activities for some units. A few students like to play soccer, floor hockey, and lacrosse, while most like basketball. We tell everybody that they can't play their favorite sport all the time. They have to give other sports a chance.

Bill admitted that 2-week units were not conducive to learning the skills or knowledge base associated with a particular sport:

We are not interested in creating Olympic athletes here. We just want students to have an opportunity to work with a lot of different people. By changing sport teams every few weeks students can be on a team with just about everybody in class sometime during the year.

Several teachers pointed out the importance of exposing students to activities that they had never seen or participated in. This was seen as educational, just as exposure to ideas in social studies or history opens new opportunities for students. Joan focused on gymnastics events for her high school students:

Many of my students have never had the opportunity to try gymnastics. Now they are 15 and 16 years old. It is very difficult to learn the skills. They just don't have the muscular strength in relation to their body size necessary to do the stunts. But I don't expect them to be elite athletes. I want them to have a chance to get up on the uneven bars or the rings and try a few very simple movements. I want them to have the opportunity to put several moves together to form a routine. If they are willing to participate, they will get an acceptable grade. The fact is they are up there, attempting it. They may not get any better than they are now, but at least 
they are learning what it's all about. They are doing something. . . . I want to reinforce that.

Teachers were continually working to encourage students to get involved in the program. They pointed out that the particular background of these urban students made "the job of getting them involved that much more difficult." Ron explained:

Some kids are just not interested in our program or in school, even at seventh and eighth grade. They are thinking about jobs. They are thinking about getting out of school. We have had some students who were suspended and come back, and they are not motivated. But we somehow manage to get them dressed and get them out there, and they get to enjoying it, and they go on. I know that we won't get $100 \%$ participation. You work with $5 \%$ detractors or problem students, and sometimes you are just not able to teach. If you have to spend time with 2 students when the other 28 are motivated to go, it takes away a lot.

\section{Task Selection}

The majority of tasks included in the middle school programs involved large group activities, most often sport. Teachers pointed out that they chose these activities because they offered students an opportunity to interact and because they had large classes and limited equipment. High school programs that emphasized cooperation and teamwork focused on individual activities performed as a group member. These included individual sports or activities in which students learned the skill with the assistance of others and practiced in the presence of the group.

Large Group Activities. Large group activities often involved 8 to 12 students and were structured to encourage all students to participate. Bob explained that he and Sue typically designated group leaders or team captains based on students' knowledge of the activity and their ability to encourage harmony within the group:

We choose captains that can get along with the group and get everybody to mix in. We put the captains in charge, and then we stress cooperation. We resolve any major conflicts that arise. We pick captains that we hope will be fair and let everybody try the positions they want to. There are times when we have to get on the captains about letting everybody get involved so that it helps their team. We stress teamwork, cooperation, and we get them involved.

Selecting captains and placing students on teams to facilitate cooperation and teamwork was a central issue for these teachers. They also made an effort to mix girls and boys and black, Hispanic, and white students on each team. Sally commented that the school principal had asked the physical education teachers why their grades for black and white students "were so close together, while black and white students' grades in other subject areas were so far apart."' Sally and Ron decided there were several factors involved: 
Sally: We don't require homework, in most cases-so parental supervision does not play a large part in the grade. Also we make an effort to have different people on different teams.

Ron: We have captains pick the team members, alternating black and white students and girls and boys. We try to keep the social cliques from dominating our classes. Everybody must meet different people and find a way to get along in order to accomplish the team goal.

Large group activities were selected not only to support content decisions associated with cooperation and teamwork, but to address the large class sizes prominent in the middle school programs. As class sizes had increased within this metropolitan school district, facilities and resources such as equipment had not kept pace. Jocelyn argued that they had to encourage cooperation and teamwork as primary goals because they were unable to contend with large groups of divisive students:

We started 4 years ago with 600 students in our school, and now we are pushing 900 . When we get five classes in the gym with 35 students in each class, they are like sardines in there. When you have a class of 25-28, that's great. But as the classes get larger, every kid over 25 seems like 2, and everyone over 30 seems like 5 . Problems don't simply multiply with more students, they increase exponentially.

Group Structures for Individual Tasks. High school programs focused less on large, team activities and more on small groups or squads. Teachers selected individually oriented tasks but organized students in small groups to practice. The teachers pointed out that their students worked better with peer support than by working alone. They preferred to have others close by to offer feedback and, when the group was focused on the activity, to keep each other on task. Teachers emphasized the importance of assisting others in the group for instructional and safety reasons. Tom encouraged students to work with partners and in groups of three in his weight-lifting class to assist students to learn teamwork and responsibility to others:

In the weight room you have to be vigilant every second, because someone else is counting on you. Each person has a role. The weight lifter has to push on the weight and lock his arms. You wait until the weight is on the rack before you let go. As soon as the spotter touches the bar, you don't let go. I never think about them not cooperating with each other, because of the partner relationship. We spend so much time teaching them how and when to spot and how very important it is.

Students frequently were taught the skill component of the content as a large group and then given an assignment to complete either individually, with a partner, or in a small group. Betty reported that some students did not know how to organize their time and were often unprepared when required to perform the skill or routine:

Most routines I compose and give to them. They have to memorize and perform them individually at the end of the unit. The individual scores for 
each team member are totalled to become the team score. I'll say, "You can continue to practice your other routine while I am working with these students over here." But if they want to go sit somewhere and hide, they can. They can mill around, spend the whole period without having done a lot. Then, when it's time to grade they say, "We're not ready. We can't do this. We haven't practiced."' Well, whose fault is that? . . . And they do learn, because I keep telling them that they are responsible to their team and to themselves, and this is what you have to do to be successful.

Teachers selected particular task structures to convey the teamwork, cooperation, and involvement goals that were central to their content. Middle school teachers used primarily team-sport structures in which students worked cooperatively to achieve a common goal. They also pointed out that these structures were almost essential because of large class sizes and limited equipment. High school teachers selected content primarily related to individual activities. They reported that their emphasis on cooperation, teamwork, and involvement required that individual activities be conducted in small groups. They emphasized that students preferred to work in groups rather than individually and seemed, in most instances, to stay on task when they had a partner to offer support and encouragement.

\section{Discussion}

The content and task decisions emphasized by teachers in this urban school district appeared to be more consistent with the goals of cooperation and respect for others within the social responsibility value orientation than with goals of social justice and reform conceptualized as social reconstruction. Teachers' content decisions centered around teaching cooperation, teamwork, and involvement for both middle and high school students. They selected large group activities at the middle school and individual activities learned and performed in small groups at the high school to convey this content to students. Social responsibility is a component of the larger construct of social competence. Social competence includes both intrapersonal skills associated with a sense of personal agency or the belief that one is capable of acting successfully, and intrapersonal skills related to the promotion of self and others within social settings (Ford et al., 1989). Articulated as goals for curricular decision making, interpersonal social goals can include both those associated with social justice or reconstruction and goals that focus on respect and responsibility. Social reconstruction advocates construct goals to increase student awareness of inequities in their school and community. Advocates encourage students to develop a commitment to change existing conditions and strategies to facilitate this change (Banks, 1991; Bell, 1991). Although social reconstruction values are strongly advocated by curriculum scholars, they have received less attention at the school level (Eisner, 1992).

Social responsibility advocates focus on the extent to which individuals work together and demonstrate respect for others. Central to the definition is the ability to avoid disruptive or violent behavior and to demonstrate characteristics of responsible citizenship. In schools, social responsibility is an influential factor in readiness to learn, setting the stage for skills associated with listening, following directions, and completing assignments (Wentzel, 1991a). Although most teachers 
include social responsibility skills as part of class management (LeCompte, 1978; McBride et al., 1986), teachers who place a high priority on these skills discuss explicit curriculum goals that assist students to work with others, demonstrate respect, and act responsibly. Objectives and tasks are designed to provide opportunities for students to interact positively and to experience concretely the results of responsible action (Wentzel, 1991b).

Wentzel (1991a, p. 1066) suggested that socially responsible behavior reflects adherence to social rules and role expectations essential for social interaction. She pointed out that cooperation, respect for others, and positive forms of group participation are essential for developing social responsibility. Teachers in the current study explicitly stated goals for cooperation, teamwork, and involvement as a central focus of their curriculum. Although some teachers used the traditional knowledge base (e.g., skills and fitness) as a means to the end of social responsibility, several teachers appeared to disregard the traditional knowledgeoriented content in favor of a strong focus on social interaction. For the middle school teachers, sport provided the task structure for cooperative interaction, but there was little emphasis on teaching skills and knowledge necessary to perform skillfully in game situations.

Teachers in physical education have been criticized for ignoring the knowledge-based content and simply keeping their students "happy, busy, and good" (Placek, 1984). Although undoubtedly there are teachers who attempt to survive the day with as little difficulty as possible, there also appear to be others who are working diligently to increase student performance on educational goals other than skills and fitness, in this case those specifically related to social responsibility. The findings of this study confirm those found by Placek. Teachers in this study did attempt to keep students happy, busy, and good. However, because of the educational and social context in which they worked, these teachers argued that this was a central part of their job.

Teachers seemed to make an effort to keep students "happy." They reported that students often were not happy with their lives and social situation in school. They encouraged students to become involved and stay involved in class and school activities, a necessary, though insufficient, component of the cooperative process. This does not mean that they catered excessively to student whims but that they were sensitive to cultural and neighborhood differences that led to activity preferences.

The teachers in this study readily admitted they were working to keep students involved or "busy" with cooperative and teamwork content. They perceived that their students were primarily sedentary and not involved in physical activity on a regular basis. Being busy in these classes meant participating in class activities. They encouraged students to focus on problem-solving strategies at appropriate levels of complexity and difficulty. These could be as simple as ordering a batting lineup or as complex as learning and practicing a gymnastics routine with other team members.

Teachers were also attempting to keep students "good." They reported that students had difficulty solving their social problems through discussion and were often willing to solve disagreements through physical violence. Violence was often just below the surface in these schools and classrooms. Teachers were vigilant to focus students' efforts on strategies to work together and to affiliate with a team to accomplish positive group goals (Ford et al., 1989). They readily 
admitted sacrificing academic goals in favor of interpersonal skill development. The "happy, busy, good" phrase is often used in a pejorative sense to criticize teachers who merely supervise physical activity rather than teach physical education. However, it is important to acknowledge that in some situations, in which students are not positive in their approach to education, involved in activity, or socialized to solve problems through discussion and compromise, educational approaches may attempt to address these concerns through explicit curricular goals. These teachers argued that for these students, social goals include keeping students "'happy, busy, and good." Findings from this research suggest teachers do indeed have strategies to implement personal-social goals. The strategies are quite different from those used to teach skills and fitness and to lead to other learning outcomes that these teachers judged to be important for their students.

One avenue used by teachers to encourage students from different neighborhoods to work cooperatively involved mixing students in teams and groups so that they would get to know each other better and be more willing to associate with others. Teachers reported their primary goal was participation, not social reform. They did not discuss individual differences or have students develop rules or strategies to increase equity in the classroom. When teams were unequal, teachers intervened to correct the problem. Students were passive in the intervention process. Teachers reported that equal teams led to greater participation and fewer management problems. The ability to cooperate enabled students to work together successfully in overcrowded situations in which the equipment was limited. Although these goals could be used as a means to encourage social reform, teachers in these high schools reported they were predominately concerned with creating an environment in which students learned to cooperate and participate in positive social activities.

Rationales for content selection associated with social responsibility appeared directly related to the school context in which teachers taught. The majority of teachers cited both student background and crowded teaching conditions as influential in their decisions to select cooperation, teamwork, and involvement goals. They indicated that students had difficulty interacting effectively and often resorted to violence in solving their problems. Teachers reported that team and group activities in which the rules for behavior were concrete and consistently enforced, such as in sports, were ideal environments for students to practice cooperative behavior. These teachers perceived that careful attention to group membership, captain and team selection, and incentives for team affiliation were relatively effective in funnelling student behavior within prosocial parameters.

The social responsibility value orientation appeared to be influential in decision making in these urban school setting. Social responsibility was described as a primary goal for physical education by many teachers and not simply as process goals leading to the development of skill or playing ability in sport. Although the teachers had been attracted to the VOI items within the social reconstruction value orientation, this research suggested that their content decisions and task selection were more consistent with the social responsibility orientation. These findings supported those by Ennis, Ross, and Chen (1992) and suggested that the VOI should be revised to reflect a stronger emphasis on social responsibility. Supervisors should be sensitive to the role of social responsibility in the development of curricular goals in urban school settings. Content and tasks to develop cooperation, teamwork, and involvement may be 
a high priority in program and lesson planning. These goals are seen by some teachers as essential for encouraging prosocial behaviors in fostering productive group activities necessary for effective interpersonal relationships.

\section{References}

Apple, M.W. (1982). Education and power. Boston: ARK.

Atkins, E. (1986). The deliberative process: An analysis from three perspectives. Journal of Curriculum and Supervision, 1, 265-293.

Banks, J.A. (1991). A curriculum for empowerment, action and change. In C.E. Sleeter (Ed.), Empowerment through multicultural education (pp. 125-141). Albany: State University of New York Press.

Bell, L.A. (1991). Changing our ideas about ourselves: Group consciousness raising with elementary school girls as a means to empowerment. In. C.E. Sleeter (Ed.), Empowerment through multicultural education (pp. 229-250). Albany: State University of New York Press.

Bloom, B.S. (1981). All our children learning. New York: McGraw-Hill.

Bruner, J.S. (1977). The process of education. Cambridge, MA: Harvard University Press.

Colwell, T. (1985). The ecological perspective in John Dewey's philosophy of education. Educational Theory, 35, 255-266.

Cohn, D. (1992, March 14). Classrooms caught in the cross-fire: Armed youths at schools are more common, bolder and younger. Washington Post, pp. 1, 14.

Dewey, J. (1916). Democracy and education. New York: Macmillan.

Eisner, E.W. (1992). Curriculum ideologies. In P.W. Jackson (Ed.), Handbook of research on curriculum (pp. 302-326). New York: Macmillan.

Eisner, E.W., \& Vallance, E. (Eds.) (1974). Conflicting conceptions of curriculum. Berkeley, CA: McCutchan.

Ennis, C.D. (1992). The influence of value orientations in curricular decision making. Quest, 44, 317-329.

Ennis, C.D., Chen, A., \& Ross, J. (1992). Educational value orientations as a theoretical framework for experienced urban teachers' curricular decision making. Journal of Research and Development in Education, 25, 156-163.

Ennis, C.D., \& Hooper, L.M. (1988). Development of an instrument for assessing educational value orientations. Journal of Curriculum Studies, 20, 277-280.

Ennis, C.D., Ross, J., \& Chen, A. (1992). The role of value orientations in curricular decision making: A rationale for teachers' goals and expectations. Research Quarterly for Exercise and Sport, 63, 38-47.

Ennis, C.D., \& Zhu, W. (1991). Value orientations: A description of teachers' goals for student learning. Research Quarterly for Exercise and Sport, 62, 33-40.

Ford, M.E., Wentzel, K.R., Wood, D., Stevens, E., \& Siesfeld, G.A. (1989). Processes associated with integrative social competence: Emotional and contextual influences on adolescent social responsibility. Journal of Adolescent Research, 4, 405-425.

Glaser, B.G., \& Strauss, A.L. (1967). The discovery of grounded theory: Strategies for qualitative research. New York: Aldine.

Goetz, J.P., \& LeCompte, M.D. (1984). Ethnography and qualitative design in educational research. Orlando, FL: Academic Press.

Griffin, P.S. (1985). Teachers' perceptions of and responses to sex equity problems in a middle school physical education program. Research Quarterly for Exercise and Sport, 56, 103-110. 
Hellison, D. (1985). Goals and strategies for teaching physical education. Champaign, IL: Human Kinetics.

Jewett, A.E., \& Ennis, C.D. (1990). Ecological integration as a value orientation for curricular decision making. Journal of Curriculum and Supervision, 5, 120-131.

Jewett, A.E., \& Mullan, M.R. (1977). Curriculum design: Purposes and processes in physical education teaching-learning. Reston, VA: American Alliance for Health, Physical Education, Recreation, and Dance.

Kliebard, H.M. (1988). The effort to reconstruct the modern American curriculum. In L.E. Beyer \& M.W. Apple (Eds.), The curriculum: Problems, politics and possibilities (pp. 19-31). Albany, NY: State University of New York Press.

Lawson, H.A., \& Placek, J.H. (1981). Physical education in the secondary schools: Curricular alternatives. Boston: Allyn \& Bacon.

LeCompte, M.D. (1978). Establishing a workplace: Teacher control in the classroom. Education and Urban Society, 11, 87-106.

Maslow, A.H. (1979). Humanistic education. Journal of Humanistic Psychology, 19, 1327.

McBride, R.E., Boggess, T.E., \& Griffey, D.G. (1986). Concerns of inservice physical education teachers as compared with Fuller's concern model. Journal of Teaching in Physical Education, 5, 149-156.

McNeil, J.D. (1990). Curriculum: A comprehensive introduction. Boston: Little, Brown.

Page, R. N. (1990). Games of chance: The lower track curriculum in a college-preparatory high school. Curriculum Inquiry, 20, 249-281.

Placek, J.H. (1984). A multi-case study of teacher planning in physical education. Journal of Teaching in Physical Education, 4, 39-49.

Rink, J. E. (1993). Teaching physical education for learning. St. Louis: Times Mirror/ Mosby.

Rockett, S., \& Owens, M. (1977). Every child a winner lesson plans. Ocilla, GA: Project Hope, Title III, Elementary and Secondary Education Act.

Rogers, C. (1983). Freedom to learn. Columbus, OH: Merrill.

Siedentop. D. (1991). Developing teaching skills in physical education. Mountain View, CA: Mayfield.

Solomon, D., Watson, M.S., Delucchi, K.L., Schaps, E., \& Battistich, V. (1988). Enhancing children's prosocial behavior in the classroom. American Educational Research Journal, 25, 527-554.

Wentzel, K.R. (1991a). Relations between social competence and academic achievement in early adolescence. Child Development, 62, 1066-1078.

Wentzel, K.R. (1991b). Social competence at school: Relation between social responsibility and academic achievement. Review of Educational Research, 61, 1-24. 